\title{
FDA finally approves BST for milk production
}

The WASHINGTON, D.C.-The Food and Drug Administration (FDA, Bethesda, MD) has granted marketing approval to Monsanto's (St. Louis, MO) recombinant version of bovine somatotropin (BST), an injectable hormone that boosts milk production in dairy cows up to 15 percent. With FDA approval, the longstanding controversy over BST will soon shift to the marketplace, where critics are promising to stage mass boycotts of milk and other products derived from BST-treated animals. Commercialization will be delayed, however, because federal legislation bars BST from sale pending a 90-day review period following approval.

BST has been subject to extensive safety, efficacy, and economic reviews for more than a decade. Signs that FDA was getting ready for a decision about the product came earlier this year, when agency officials convened two advisory committees to consider unsettled BSTrelated safety and labeling issues.

At the first advisory-committee meeting in March, which focused on safety issues, FDA's Veterinary Medicine Advisory Committee (VMAC) concluded that, although BST increases the incidence of mastitis when used to augment milk production by dairy cows, its use does not pose a significant risk to public health. The VMAC also concluded that current safeguards are adequate to prevent unsafe levels of antibiotics, which are used to treat mastitis, from contaminating the milk supply.
At the second advisory-committee meeting in May, the FDA asked panelists to consider whether products from cows treated with BST need to be labeled. The panel was told that its deliberations pertained not only to Monsanto's product but also to three other similar versions under development by American Cyanamid (Wayne, NJ), Eli Lilly (Indianapolis, IN), and Upjohn (Kalamazoo, MI). The opinions of the committee members-who were drawn from the FDA's new Food Advisory Committee as well as from the VMAC-were divided, with two-thirds against labeling and onethird strongly in favor of labels.

Since then, FDA officials have concluded that the agency "lacks a legal basis to require special labeling of these foods." However, agency officials have noted that "food companies may voluntarily label their products, provided that information is truthful and not misleading." In the case of BST, food companies opposed to BST can note that their products come from cows not treated with BST

"There is virtually no difference in milk from BST-treated and untreated cows," says FDA Commissioner David Kessler. "We have looked carefully at every single question raised, and we are confident that this product is safe for consumers, cows, and for the environment. The public can be confident that milk and meat from BST-treated cows is safe to consume."

Nonetheless, the FDA is requiring Monsanto to establish an extensive post-marketing monitoring program for BST. Requirements include tracking milk production and associated antibiotic residues in BST-treated herds for two years in 21 top milk-producing states, comparing how much milk is discarded because of excessive antibiotic residues from BST-treated herds versus untreated herds, tracking BSTrelated complaints, and developing a program to observe closely 24 commercial herds for mastitis, antibiotic use, and milk discarded because of antibiotic residues.

Monsanto, which will sell its version of BST under the tradename Posilac, says that dairy farmers who use the product on their herds will benefit from higher efficiencies and enhanced milk-production levels. Hormone injections every two weeks increase a cow's production yields by about $10-15$ percent, raising an animal's total annual milk output to about 17,000 pounds.

However, critics of the product claim that it will put small farmers out of business. Jeremy Rifkin of the Foundation on Economic Trends (Washington, DC) says that he has nearly 20,000 activists preparing to join in a nationwide boycott of milk and other products derived from BST-treated cows. And Senator Russell Feingold (D-WI), who sponsored a budget amendment last summer that imposes the current 90-day moratorium on BST sales, says that he has plans to introduce legislation to further delay BST sales.

—Jeffrey L. Fox

\section{Do flagship-product failures cheat investors?}

NEW YORK - Should an investor feel ripped off when a biopharmaceutical firm drops its flagship product? After all, faith in that product is often why an investor bought stock in the firm in the first place.

Both DNX (Princeton, NJ) and Idec Pharmaceuticals (La Jolla, CA) were recently forced to answer that question, as both canned their lead products. DNX backed away from its recombinant-hemoglobin blood substitute, while Idec deep-sixed its panel of anti-idiotypic monoclonal antibodies (MAbs) for B-cell lymphoma.

Surprisingly, the consensus is that investors aren't cheated by flagship-product failures. "Did management intentionally deceive investors? Or did a product fail because product development is inherently risky? Probably the latter, although management is nevercom- pletely blameless," comments R. Brandon Fradd, a biotech analyst at Montgomery Securities (San Francisco, CA). Fradd points out, moreover, that in its 1983 initial public offering (IPO), Amgen (Thousand Oaks, CA) didn't emphasize erythropoietin and didn't even mention granulocyte colony-stimulating factor, its two current blockbusters. "If you bought Amgen's IPO stock and held it, you got a good return, 